\title{
The CBI Receptor Antagonist AM25I Impairs Reconsolidation of Pavlovian Fear Memory in the Rat Basolateral Amygdala
}

\author{
Patrizia Ratano ${ }^{1,2}$, Barry J Everitt' and Amy L Milton*,' \\ 'Behavioural and Clinical Neuroscience Institute, Department of Psychology, University of Cambridge, Cambridge, UK; ${ }^{2}$ Department of Physiology \\ and Pharmacology, Sapienza University of Rome, Rome, Italy
}

\begin{abstract}
We have investigated the requirement for signaling at $\mathrm{CB}$ I receptors in the reconsolidation of a previously consolidated auditory fear memory, by infusing the $\mathrm{CBI}$ receptor antagonist AM25I, or the FAAH inhibitor URB597, directly into the basolateral amygdala (BLA) in conjunction with memory reactivation. AM25 I disrupted memory restabilization, but only when administered after reactivation. URB597 produced a small, transient enhancement of memory restabilization when administered after reactivation. The amnestic effect of AM25 I was rescued by coadministration of the $G_{A B A}$ receptor antagonist bicuculline at reactivation, indicating that the disruption of reconsolidation was mediated by altered GABAergic transmission in the BLA. These data show that the endocannabinoid system in the $B L A$ is an important modulator of fear memory reconsolidation and that its effects on memory are mediated by an interaction with the GABAergic system. Thus, targeting the endocannabinoid system may have therapeutic potential to reduce the impact of maladaptive memories in neuropsychiatric disorders such as posttraumatic stress disorder.

Neuropsychopharmacology (2014) 39, 2529-2537; doi:I0.1038/npp.2014.103; published online 4 June 2014
\end{abstract}

\section{INTRODUCTION}

Memory reconsolidation is the process by which a wellconsolidated memory returns to a labile state and becomes susceptible to manipulation (Lewis, 1979; Nader, 2003). This process has been extensively investigated in the context of pavlovian conditioned fear memories, where pharmacological manipulation at memory reactivation can prevent (Dębiec et al, 2002; Milton et al, 2013; Nader et al, 2000) or enhance (Lee et al, 2006) the subsequent expression of the conditioned fear response. Thus, it has been argued that targeting the reconsolidation process may provide a novel means of disrupting maladaptive memories in neuropsychiatric disorders such as posttraumatic stress disorder (PTSD; Brunet et al, 2008; Schiller et al, 2010), persistently reducing symptoms of the disorder following only a single (or few) treatment sessions combining behavioral and pharmacological therapy. However, any amnestic agent used in the clinic ideally should not also have adverse side effects; therefore, identifying new drug targets for disrupting memory reconsolidation is of critical importance in translating these promising findings to the clinic.

\footnotetext{
*Correspondence: Dr AL Milton, Department of Psychology, University of Cambridge, Downing Site, Cambridge CB2 3EB, UK, Tel: +44 I 223 333593, Fax: +44 1223 333564, E-mail: alm46@cam.ac.uk Received 20 January 2014; revised 30 April 2014; accepted 30 April 20I4; accepted article preview online 7 May 2014
}

Drugs that alter levels of endogenous endocannabinoids may provide a new drug target for treating psychiatric disorders using reconsolidation-based therapies. Growing evidence indicates a fundamental role for the endocannabinoid system in regulating memory consolidation (Campolongo et al, 2009; Hauer et al, 2011). However, less is known about endocannabinoid signaling in reconsolidation (De Oliveira Alvares et al, 2008; Kobilo et al, 2007), especially within the amygdala (Bucherelli et al, 2006; Lin et al, 2006). Furthermore, the involvement of endocannabinoid signaling in the reconsolidation process may not be straightforward, with apparently conflicting results having been reported in the literature: whereas agonism and antagonism at endocannabinoid receptors (CBRs) bidirectionally modulated the reconsolidation of aversive memories by respectively enhancing and impairing memory (De Oliveira Alvares et al, 2008; Suzuki et al, 2008), the CBR agonist, WIN55,212-2 impaired reconsolidation in fear-potentiated startle procedures after CS reexposure (Lin et al, 2006). Treatment with the CBR subtype 1 (CB1R) antagonist rimonabant neither enhanced pavlovian fear memory nor resulted in amnesia (Suzuki et al, 2004); however, rather than indicating that reconsolidation is not dependent on CB1Rs, these data may instead reflect a requirement for CB1Rs in the destabilization of memory (Suzuki et al, 2008). As the effects of blocking the restabilization of a reconsolidating memory can only be seen when memory destabilization has occurred (Ben Mamou et al, 2006; Milton et al, 2013), we hypothesized 
that the timing of the endocannabinoid treatment may be critical in determining the behavioral outcome of the memory manipulation; we therefore predicted that if endocannabinoid signaling manipulations can disrupt memory destabilization or restabilization depending on treatment timing, amnesia would only be observed if the endocannabinoid system was targeted after memory reactivation. This is critically important for the future translation of reconsolidation-based therapies to the clinic.

Here, we have employed the widely used pavlovian fear conditioning rodent model of PTSD that encompasses some of its key behavioral and physiological symptoms (Dębiec and LeDoux, 2004; Johansen et al, 2011; Mahan and Ressler, 2012) to test the hypotheses that: (1) the restabilization of an auditory fear memory would only be impaired if cannabinoid compounds were given following a memory reactivation session; (2) memory restabilization would be enhanced by increasing endocannabinoid signaling; and (3) the requirement for endocannabinoids in reconsolidation would depend upon GABAergic transmission in the basolateral amygdala (BLA). To investigate the necessity of $\mathrm{CB} 1 \mathrm{R}$ activation for mnemonic processes, we used the CB1R antagonist AM251. However, as the use of drugs that directly bind and activate brain CBRs, such as WIN55,212-2 administered systemically, may ultimately be precluded from human clinical use by their abuse liability (Fattore et al, 2001), we chose to use the fatty-acid amide hydroxylase (FAAH) inhibitor URB597 (URB) that increases endogenous cannabinoid levels, and that has no rewarding or reinforcing effects when given systemically (Piomelli et al, 2006). Therefore, animals with a well-consolidated auditory fear memory were infused with either URB or the CB1R antagonist AM251 (AM) into the BLA, either before or after fear memory reactivation. As endocannabinoids are hypothesized to regulate GABAergic signaling within the BLA (Azad et al, 2004), particularly at the $\mathrm{GABA}_{\mathrm{A}}$ subtype of receptor (Katona et al, 2001), we also investigated whether antagonism at GABAergic receptors could rescue any memory deficit induced by CB1R blockade.

\section{MATERIALS AND METHODS}

\section{Subjects}

A total of 122 male Lister hooded rats (300-320 g at the time of surgery, Charles River, Bicester, UK) were pair-housed on a reversed light-dark cycle (lights on at $1900 \mathrm{~h}$ ). All subjects were fed $25 \mathrm{~g}$ per rat after behavioral procedures each day starting from the day of surgery; this amount of food maintains animals at a weight comparable to animals that receive food ad libitum. Water was available ad libitum except during the behavioral and infusion procedures. All procedures were conducted in accordance with the UK Animals (Scientific Procedures) Act 1986.

\section{Surgery}

Rats were anesthetized with a mixture (i.m.) of ketamine ( $80 \mathrm{mg} / \mathrm{kg}$; Ketaset, Pfizer, Walton-on-the-Hill, UK) and xylazine (10 mg/kg; Rompun, Bayer, Newbury, UK) and implanted with bilateral guide cannulae $(16 \mathrm{~mm}, 24$ gauge; Coopers Needle Works, Birmingham, UK) just dorsal to the
BLA, as described previously (Milton et al, 2008) with coordinates of $\mathrm{AP}-2.6 \mathrm{~mm}$ and $\mathrm{ML} \pm 4.5 \mathrm{~mm}$ (from bregma) and DV $-5.6 \mathrm{~mm}$ (from dura). Stainless steel obdurators (Coopers Needle Works) were inserted into both cannulae to maintain patency. A recovery period of at least 7 days was given before behavioral testing.

\section{Drug Infusions}

Drugs were infused into the BLA using a syringe pump (Harvard Apparatus, Edenbridge, UK) and $5 \mu$ l Hamilton syringes, connected to injectors (28 gauge, projecting $2 \mathrm{~mm}$ beyond the guide cannulae; Bilaney, Sevenoaks, UK) by polyethylene tubing. All infusions were begun $30 \mathrm{~s}$ after the insertion of the injectors and performed over $2 \mathrm{~min}$ at a rate of $0.25 \mu \mathrm{l}$ per min (total volume of $0.5 \mu \mathrm{l}$ per side). The injectors were left in place for a further $1 \mathrm{~min}$ after the end of the infusion to allow the drugs to diffuse from the injection site. Although it is anticipated that the effects of infusions delivered at this rate and volume should be largely restricted to the BLA, we cannot exclude that the compounds may have also affected other amygdala nuclei. URB597 (Mor et al, 2004), a FAAH inhibitor (URB (cyclohexylcarbamic acid 3-carbamoyl-biphenyl-3-yl ester), $30 \mathrm{ng}$ per $0.5 \mu \mathrm{l}$ per side, Sigma-Aldrich, Dorset, UK), the CB1R antagonist AM251 (Lan et al, 1999; AM ( $N$-(Piperidin1-yl)-5-(4-iodophenyl)-1-(2,4-dichlorophenyl)-4-methyl-

$1 \mathrm{H}$-pyrazole-3 carboxamide), $300 \mathrm{ng}$ per $0.5 \mu \mathrm{l}$ per side, Tocris, Bristol, $\mathrm{UK})$, and $\mathrm{GABA}_{\mathrm{A}}$ receptor antagonist $1(\mathrm{~S}), 9(\mathrm{R})-(-)$-Bicuculline methiodide (BIC; $50 \mathrm{ng}$ per $0.5 \mu$ per side, Sigma-Aldrich) were dissolved in a vehicle (VEH) containing 5\% polyethylene glycol, 5\% Tween-80, and $90 \%$ saline. Dose-response curves for these drugs in fear memory tasks have been reported previously in the literature, and hence the doses used in the current work were chosen based on previous studies: the URB dose used is higher than the dose required to enhance the consolidation of inhibitory avoidance (IA) memory (Campolongo, 2010; Ratano et al, 2011); the AM dose is within the range that impairs olfactory fear conditioning (Tan et al, 2011) and higher than the dose that impairs the consolidation of IA memory (Campolongo et al, 2009); the dose of BIC impairs the consolidation of IA memory (Dickinson-Anson and McGaugh, 1997) and also the extinction of contextual fear memory (Berlau and McGaugh, 2006).

\section{Histology}

After behavioral testing was completed, rats received an overdose of sodium pentobarbital (Dolethal; Rhone-Merieux, Harlow, UK) and were transcardially perfused with $0.01 \mathrm{M}$ PBS, followed by $4 \%$ paraformaldehyde (PFA). Brains were collected and stored in 4\% PFA for at least $24 \mathrm{~h}$, before being transferred to $20 \%$ sucrose solution for cryoprotection before sectioning. The brains were sectioned coronally at $60 \mu \mathrm{m}$, stained with Cresyl Violet, and the cannulae placement assessment was conducted under light microscopy (Leica). Only subjects with the injectors located bilaterally within the BLA and with no bilateral damage to the amygdala or any other area of the brain were included in the statistical analysis (Figure 1). 
a

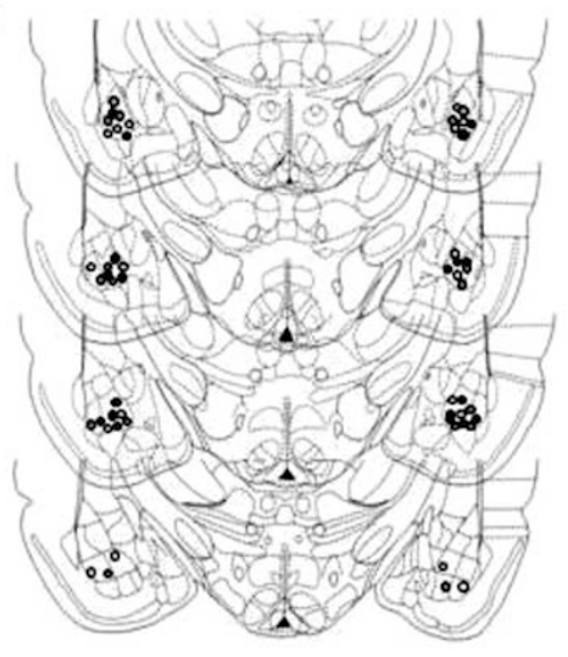

b

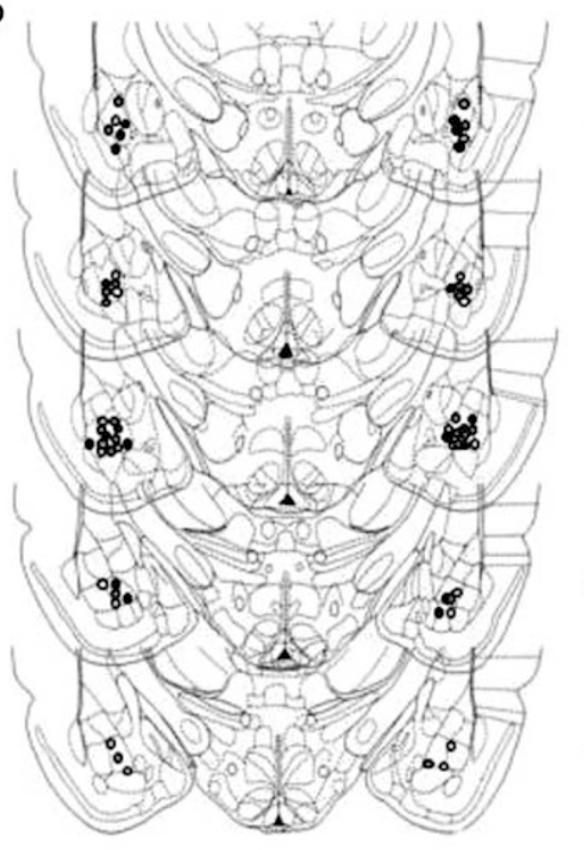

$-2.30$

$-2.56$

$-2.80$

$-3.14$

$-3.30$

$-2.12$

$-2.30$

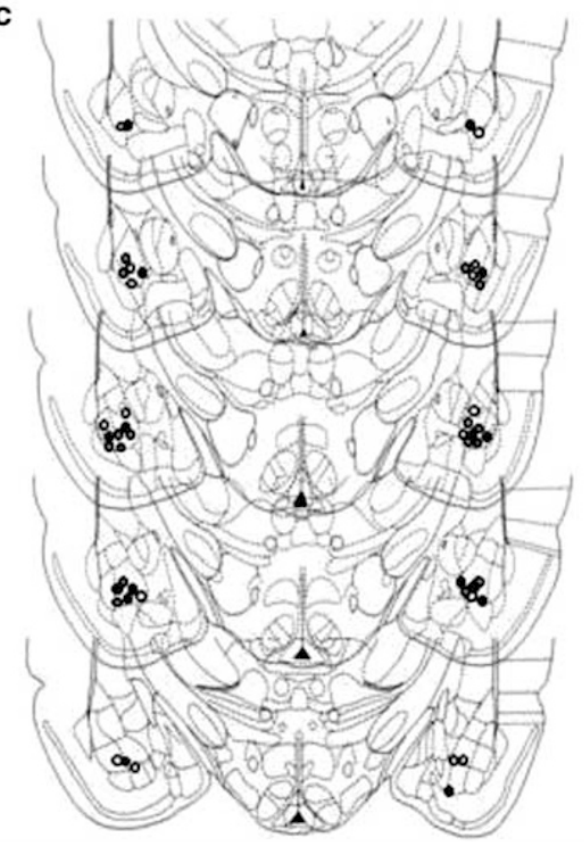

d

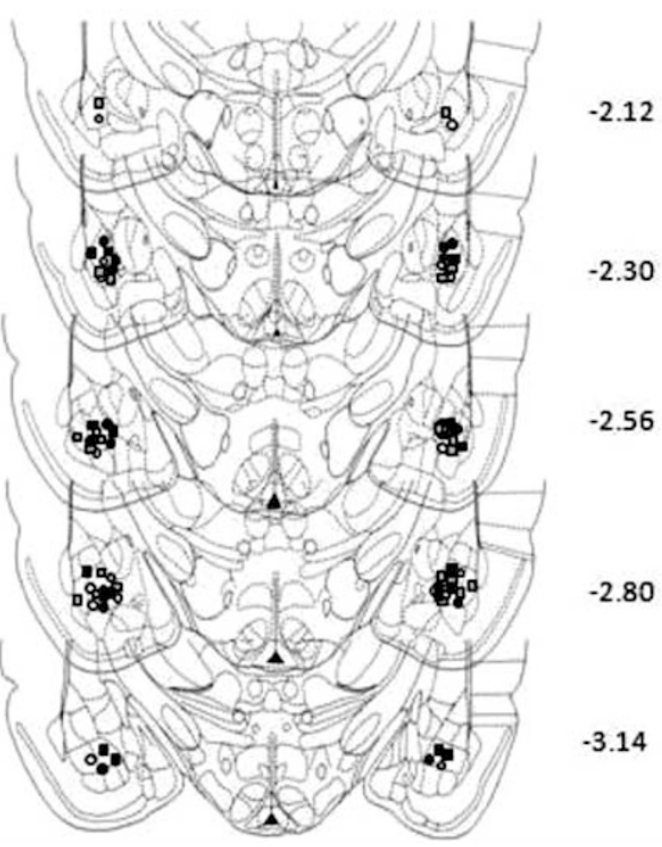

Figure I Representation of cannulae placements within the BLA. The placements for individual experiments are shown separately, and coordinates are from bregma. For each experiment ((a), administration before reactivation, (b) administration after reactivation, (c) administration without reactivation, and (d) combined endocannabinoid and GABAergic signaling manipulations), the white circles represent the vehicle group and the dark circles represent the AM25I group. The gray circles represent URB597 group $(\mathrm{a}-\mathrm{c})$, the gray squares represents the bicuculline group (d), and the dark squares represent AM+BIC group (d). This figure was modified, with permission, from Paxinos and Watson (2004).

\section{Behavioral Procedures}

Auditory fear conditioning was performed similarly to as described previously (Lee et al, 2005, 2006; Milton et al, 2013). Briefly, on day 1, rats were habituated to the conditioning chamber (Med Associates, Sandown Scientific, Hampton, UK) for $2 \mathrm{~h}$ and allowed to freely explore the context. On day 2 , the rats were placed in the same experimental context, and conditioned with two CS-US pairings. The CS was an auditory clicker $(10 \mathrm{~Hz}, 80 \mathrm{~dB}, 60 \mathrm{~s})$ and the US an electric footshock $(0.5 \mathrm{~mA}, 1 \mathrm{~s})$. The first CSUS pairing was presented after $35 \pm 1 \mathrm{~min}$ from the start of the session, followed by a $5 \pm 1 \mathrm{~min}$ interval when a second CS-US pairing was given. The conditioning session terminated $5 \mathrm{~min}$ after the last footshock delivery.

On day 3 , the fear memory was reactivated by reexposing the rats to the conditioning chamber for a 2-min session, to a single presentation of the $60 \mathrm{~s}$ CS after $60 \mathrm{~s}$ of context 
exposure. All rats received an intra-BLA infusion of drug $30 \mathrm{~min}$ before or immediately (1-5 min) after the memory reactivation session. The timing of the infusions before reactivation was based on previous studies, where URB597 enhances stress-induced analgesia when administered intracranially $35 \mathrm{~min}$ before test (Hohmann et al, 2005) and AM251 blocks the effects of CB1R agonism on the tail flick test for at least an hour after intracranial infusion (Hasanein et al, 2007). Non-reactivated control groups underwent the same behavioral procedures, except that, on day 3, the drug infusions were given in a novel room and they were not reexposed to either the training context or the CS.

Testing took place $24 \mathrm{~h}$ (postreactivation long-term memory, PR-LTM24h) and 8 days (PR-LTM8d) after reactivation to test long-term memory retention. Animals were returned to the conditioning chambers for a 2-min session where they received a single presentation of the 60-s $\mathrm{CS}$ after $60 \mathrm{~s}$ of context exposure. Freezing behavior was video-recorded, and conditioned freezing scored offline by an experimenter blind to treatment. Freezing is defined as the lack of movement except for breathing, and was assessed at $5 \mathrm{~s}$ intervals to give the percentage of time freezing. Freezing during the first minute of the testing session was assessed as measure of fear to the experimental context, and during the second as measure of fear to the CS.

\section{Statistical Analysis}

Data are presented as the mean \pm SEM and were analyzed using repeated measures ANOVA, with CS (context vs cue) and session (reactivation $v s$ PR-LTM24h vs PR-LTM8d) as within-subject factors, and drug (VEH vs URB vs AM) as between-subject factors. Where the data violated the assumption of sphericity as assessed using Mauchly's test, a correction was applied; the Greenhouse-Geisser correction if $\varepsilon<0.75$, and the Huynh-Feldt correction if $\varepsilon>0.75$, as recommended by Cardinal and Aitken (2006). Where appropriate, further ANOVAs or pairwise comparisons were conducted; all pairwise comparisons were adjusted using the Šidák correction, a mathematically accurate form of the Bonferroni estimation (Cardinal and Aitken, 2006).

\section{RESULTS}

\section{Infusion of URB597 and AM251 before Reactivation Affected Neither Retrieval nor Reconsolidation of Pavlovian Fear Memory}

In the first experiment, the FAAH inhibitor URB597 (URB) or the CB1R antagonist AM251 (AM) or vehicle (VEH) were bilaterally infused into the BLA $30 \mathrm{~min}$ before memory reactivation. All experimental groups had previously conditioned to the CS, as all rats showed a greater freezing response to the CS than to the context during the reactivation session $\left(\mathrm{F}_{1,25}=41.6, p<0.001, \eta^{2}=0.63\right)$. As shown in Figure 2, rats in all experimental groups froze similarly to the CS during the test sessions (drug: $F<1$ ), and although conditioned freezing reduced across the test sessions (session: $\mathrm{F}_{2,50}=5.83, p=0.005, \eta^{2}=0.19$ ), this extinction was the same for all experimental groups $(\mathrm{F}<1)$. Furthermore, analyzing the memory reactivation session alone showed that there were no acute effects of the drugs on the

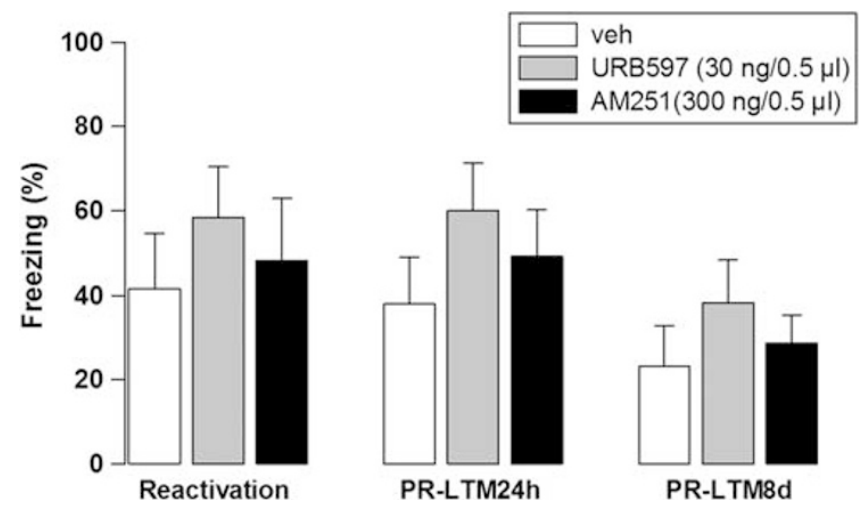

Figure 2 Effects of the FAAH inhibitor URB597 and the CBI receptor antagonist AM25I on CS-fear memory reconsolidation. Administration of URB597 or AM25I before memory reactivation had no effect on the retrieval of the CS-fear memory at reactivation and did not alter expression of freezing response at tests conducted $24 \mathrm{~h}$ or 8 days later. Group sizes were VEH, $n=9$; URB597, $n=10$; and AM25I, $n=9$.
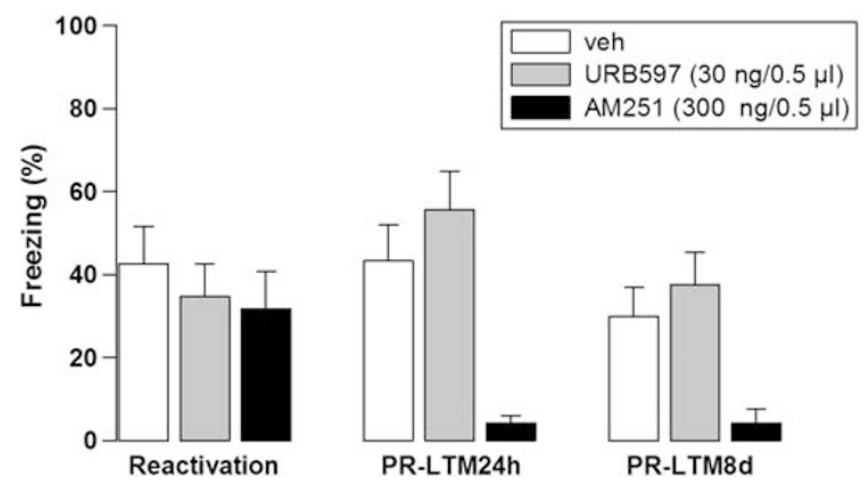

Figure 3 Effects of the FAAH inhibitor URB597 (30 ng per $0.5 \mu \mathrm{l}$ ) and the CBI receptor antagonist AM25 I (300 ng per $0.5 \mu \mathrm{l}$ ) on CS-fear memory reconsolidation. Administration of URB597 immediately after the reactivation session produced a small, transient enhancement of CS-fear memory reconsolidation at $24 \mathrm{~h}$, but not 8 days, after reactivation. AM25 I persistently impaired memory reconsolidation when compared with vehicle and URB597-treated rats after both $24 \mathrm{~h}$ and 8 days after the reactivation session. Data are presented as means \pm SEM. Group sizes were VEH, $n=10$; URB597, $n=12$; and AM251, $n=10$.

expression of conditioned freezing $(\mathrm{F}<1)$. Thus, neither URB nor AM affected memory retrieval or reconsolidation when given before memory reactivation.

\section{AM251 Infused Immediately after Reactivation Disrupted, whereas URB597 Slightly and Transiently Enhanced, Fear Memory Reconsolidation}

AM infused into the BLA immediately after memory reactivation disrupted fear memory reconsolidation as assessed at test (Figure 3). All rats had previously conditioned to the $\mathrm{CS}$, and all groups showed a greater fear response to the $\mathrm{CS}$ than to the context during the reactivation session $\left(\mathrm{F}_{1,29}=50.5, p<0.001, \eta^{2}=0.64\right)$. However, animals that received $\mathrm{AM}$ immediately after reactivation showed less freezing at test, $24 \mathrm{~h}$ later, than animals receiving URB or 
VEH (drug: $\mathrm{F}_{2,29}=6.00, p<0.01, \eta^{2}=0.29$ ) across both test sessions (session: $\mathrm{F}_{2,29}=4.78, p<0.05, \eta^{2}=0.14$ ) and all experimental groups (drug $\times$ session: $\mathrm{F}_{4,58}=5.53, p<0.001$, $\left.\eta^{2}=0.28\right)$. Rats infused with AM immediately after the reactivation session froze less at test $24 \mathrm{~h}$ after reactivation than they had during the reactivation session (reactivation vs PR-LTM24h, $p=0.011$; reactivation $v s$ PR-LTM8d, $p=0.001)$.

Rats infused with URB after reactivation showed higher levels of freezing at the $24 \mathrm{~h}$ test than they had shown during the memory reactivation session (reactivation vs PRLTM24h, $p=0.041$ ), but this increased fear response to the CS did not persist to the 8-day test (reactivation $v s$ PRLTM8d, $p=0.96$ ). Thus, intra-BLA infusion of URB may have produced a small, transient enhancement of memory reconsolidation, whereas the antagonist AM persistently disrupted reconsolidation of pavlovian fear memory.

\section{The Effects of Intra-BLA AM251 and URB597 on Memory Reconsolidation Were Dependent on Memory Reactivation}

To determine whether the effects of URB and AM on fear memory persistence were reactivation dependent, separate groups of rats were infused with URB, AM, or VEH, without undergoing memory reactivation (Figure 4). All rats had previously conditioned to the CS, as they froze more during the CS presentation than to the context $48 \mathrm{~h}$ after conditioning $\left(\mathrm{F}_{1,21}=23.5, p<0.001, \eta^{2}=0.53\right)$. Although the experimental groups did not differ from each other (drug: $F_{2,21}=0.02, p=0.98$ ), the URB-infused group did not extinguish responding across the two test sessions, unlike the $\mathrm{AM}$ and $\mathrm{VEH}$ groups (drug $\times$ session: $\mathrm{F}_{2,21}=4.57$, $\left.p<0.05, \eta^{2}=0.30\right)$. Although there was a reduction in freezing at the 8-day test for animals infused with VEH (PRLTM24h vs PR-LTM8d, $p<0.05$ ) and AM (PR-LTM24h $v s$ PR-LTM8d, $p<0.01)$, the URB-treated animals did not reduce their freezing behavior (PR-LTM24h $v s$ PR-LTM8d, $p>0.05)$. Furthermore, the nonreactivated AM-treated group showed greater freezing at the $24 \mathrm{~h}$ test than animals

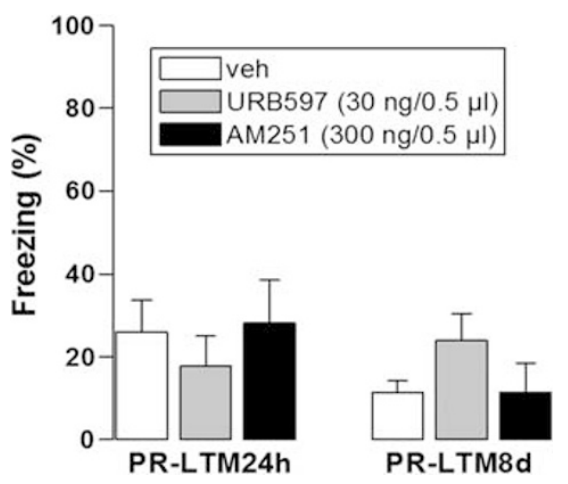

Figure 4 Effects of the FAAH inhibitor URB597 (30 ng per $0.5 \mu l$ ) and the $\mathrm{CBI}$ receptor antagonist AM25I (300 ng per $0.5 \mu \mathrm{l}$ ) on CS-fear memory reconsolidation in rats not exposed to the memory reactivation session. Administration of URB597 or AM25I in the absence of memory reactivation had no effect on the retrieval of the CS-fear memory both $24 \mathrm{~h}$ and 8 days after administration. Data are presented as means \pm SEM. Group sizes were VEH, $n=8$; URB597, $n=8$; and AM25I, $n=8$. that had received AM following memory reactivation (Figure $3 ; p<0.05$ ), indicating that the amnesia produced by AM was reactivation dependent. Thus, at $48 \mathrm{~h}$ and 9 days after conditioning, the fear memory was still intact, and the amnesia produced by AM was only seen when the drug was given in conjunction with memory reactivation.

The Disruption of Reconsolidation Produced by AM251 Was Blocked by the Administration of the $\mathrm{GABA}_{\mathrm{A}}$ Receptor Antagonist Bicuculline

In order to better understand the persistent amnesia produced by reactivation after AM administration, we investigated the interaction of endocannabinoid and GABAergic signaling within the amygdala. To test the hypothesis that the amnesia produced by the $\mathrm{CBR}$ antagonist $\mathrm{AM}$ was mediated by increased GABAergic transmission, animals were infused with the $\mathrm{GABA}_{\mathrm{A}}$ receptor antagonist $\mathrm{BIC}$, alone or in conjunction with $\mathrm{AM}$ at reactivation (Figure 5). As before, all rats had previously conditioned to the CS, and froze more during the CS presentation than to the context during the reactivation session $\left(\mathrm{F}_{1,34}=184.0, p<0.001\right.$, $\left.\eta^{2}=0.84\right)$. All rats showed equivalent levels of freezing during the reactivation session $\left(\mathrm{F}_{3,34}=1.27, p=0.30\right)$ and AM infusions after reactivation resulted in amnesia at tests $24 \mathrm{~h}$ later (drug: $\mathrm{F}_{3,34}=3.12, p<0.05, \eta^{2}=0.22$; session: $\mathrm{F}_{2,68}=55.5, p<0.001, \eta^{2}=0.62$; session $\times$ drug: $\mathrm{F}_{6,68}=4.31$, $p<0.001, \eta^{2}=0.28$ ), although administration of BIC alone had no effect relative to VEH $(p>0.99)$. Freezing was reduced at test relative to reactivation for rats that had received either AM (reactivation $v s$ PR-LTM24h, $p<0.001$; reactivation $v s$ PR-LTM8d, $p<0.001$ ), BIC alone (reactivation $v s$ PR-LTM24h, $p=0.011$; reactivation $v s$ PR-LTM8d, $p=0.001$ ), or $\mathrm{AM}+\mathrm{BIC}$ (reactivation $v s$ PR-LTM8d, $p=0.002)$. The post hoc tests showed that at test, AMtreated rats froze less than VEH-treated $(p=0.029)$ and BIC-treated rats $(p=0.017)$ and, importantly, less than animals receiving $\mathrm{AM}+\mathrm{BIC}(p=0.045)$. Thus, the disruptive

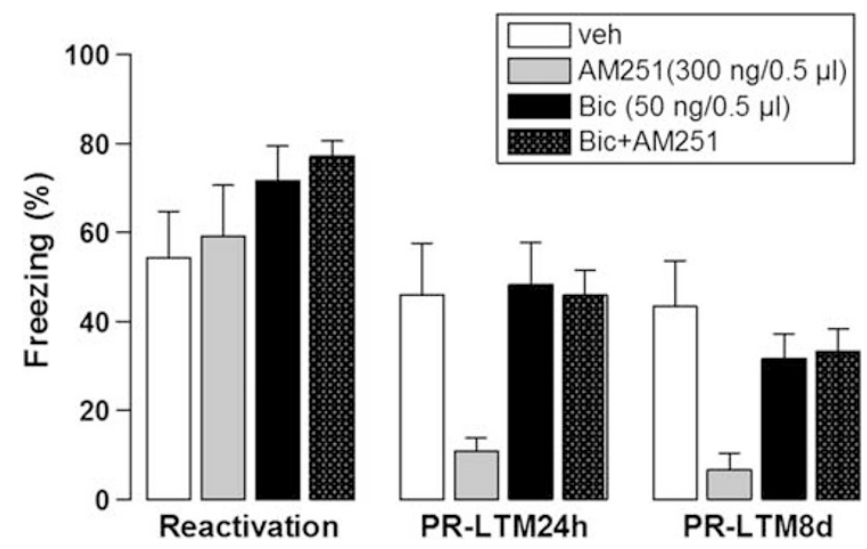

Figure 5 Effects of the CBI receptor antagonist AM25I (300 ng per $0.5 \mu \mathrm{l}$ ) or the $\mathrm{GABA}_{\mathrm{A}}$ receptor antagonist bicuculline (BIC $50 \mathrm{ng}$ per $0.5 \mu \mathrm{l}$ ) on CS-fear memory reconsolidation. Administration of AM25I immediately after the reactivation session persistently impaired the CS-fear memory both $24 \mathrm{~h}$ and 8 days after the reactivation session. Data are presented as means \pm SEM. Group sizes were VEH, $n=10$; AM25I, $n=10$; BIC, $n=10$; and $\mathrm{AM} 25 \mathrm{I}+\mathrm{BIC}, n=8$. 
effect on memory reconsolidation induced by blocking CB1Rs was replicated, and this disruption of reconsolidation could be prevented by antagonism at $\mathrm{GABA}_{\mathrm{A}}$ receptors. These results indicate that the endocannabinoid signalingmediated disruption of CS-fear memory reconsolidation depends upon the consequent increase in GABAergic transmission in the BLA.

\section{DISCUSSION}

We have demonstrated that antagonism at CB1Rs prevented fear memory reconsolidation and may offer a promising therapeutic strategy in the treatment of PTSD, while also elucidating the mechanism by which CB1R antagonism exerts its effects on anxiety. Although there are other animal models such as the single-prolonged stressor, predatorbased psychosocial stress, and predator scent stress models (see Daskalakis et al, 2013 for review) that capture different aspects of PTSD, we have shown that blocking CB1Rs within the BLA disrupted the reconsolidation of a pavlovian CSfear memory, resulting in persistent loss of fear evoked by the subsequent presentation of the CS, a change in behavior widely suggested to model a desirable outcome for PTSD treatment (Dębiec and LeDoux, 2006; Parsons and Ressler, 2013; Schiller et al, 2010). This disruption of memory reconsolidation, which persisted for at least 8 days after CS reexposure, occurred if and only if the CB1R antagonist AM251 was infused locally into the BLA immediately after retrieval; administration $30 \mathrm{~min}$ before memory reactivation did not result in an amnestic effect during the test sessions, and AM251 administration in the absence of memory reactivation did not produce amnesia. Nonreactivated groups tended to show lower levels of conditioned fear at test than animals that had been reactivated, supporting the hypothesized function for reconsolidation of memory strengthening. However, although freezing was reduced in the nonreactivated groups, it was still higher than in amnesic animals; therefore, the requirement for AM251 treatment and reactivation is more consistent with a blockade of memory restabilization than insensitivity of measurement. In contrast to the amnesia produced by AM251 given after reactivation, infusion into the BLA of the FAAH inhibitor URB597 in conjunction with memory reactivation resulted in a minor, transient enhancement of conditioned freezing. Whether a greater-or more sustained-effect would be observed with a higher dose of URB597 remains to be established, although it should also be considered that drugs targeting the endocannabinoid system often have biphasic effects (Metna-Laurent et al, 2012). Furthermore, we found that the memory impairment induced by reactivation after $\mathrm{CB} 1 \mathrm{R}$ antagonism could be prevented by coinfusion of the $\mathrm{GABA}_{\mathrm{A}}$ receptor antagonist bicuculline, suggesting that endocannabinoid-mediated signaling affects reconsolidation via modulation of GABAergic transmission in the amygdala.

The data presented here are consistent with previous work indicating a role for CB1Rs in the plasticity underlying emotional memory, and help to account for some of the apparent inconsistencies in the previous literature. CB1Rs are required for the extinction, though interestingly not the consolidation (Arenos et al, 2006; Marsicano et al, 2002), of conditioned fear memory for context-shock associations (Suzuki et al, 2004) and tone-shock associations (Marsicano et al, 2002) and enhancing CB1R transmission enhances the extinction of fear memory (Chhatwal et al, 2005). However, although it has previously been shown that antagonists at CB1Rs disrupt the consolidation of inhibitory avoidance memory (Campolongo et al, 2009), consolidation of contextual fear conditioning is impaired by the activation of CB1Rs within the hippocampus (Maćkowiak et al, 2009). We hypothesize that these apparently discrepant findings are due to the timing of the amnestic treatment. We suggest that CB1Rs are required for the process of memory destabilization, as has been shown for contextual fear memories (Suzuki et al, 2008). Although extinction is usually conceptualized as the learning of a new, inhibitory 'CS-no US' memory (Bouton, 1991), there is evidence that there are some changes in synaptic strength in the amygdala that are required for long-term storage of the original CS-fear memory (Gale et al, 2004), following extinction training (see Barad et al, 2006 for review). Our finding that blocking CB1Rs before memory reactivation did not result in amnesia is consistent with the blockade of memory destabilization (Suzuki et al, 2008), a process, it should be noted, that is doubly dissociable from memory retrieval (Milton et al, 2013). Blockade of memory destabilization would prevent memory reconsolidation from being engaged, and consequently prevent the effects of any treatment that might enhance (eg, FAAH) or disrupt (eg, AM251) reconsolidation (Lee, 2008). Mechanistically, this effect may be mediated through indirect actions on BLA pyramidal neurons. CB1Rs are located on GABAergic interneurons within the BLA (Katona et al, 2001) and act presynaptically to reduce GABAergic transmission onto BLA pyramidal neurons (Azad et al, 2003; Katona et al, 2001). Thus, we hypothesize that CB1R antagonism should act to disinhibit GABAergic interneurons, increasing the inhibition of the pyramidal neurons, and therefore preventing the neuronal activity, mediated through GluN2B-containing NMDARs (Milton et al, 2013), that is required for memory destabilization. This is a speculative hypothesis and the interactions between endocannabinoid and glutamatergic signaling in fear memory reconsolidation remain to be investigated.

When administered after memory reactivation, CB1R antagonism led to a blockade of memory restabilization that was dependent on GABAergic signaling. We hypothesize that after memory reactivation, when the destabilization process has already occurred, the disinhibition of GABAergic interneurons through $\mathrm{CB} 1 \mathrm{R}$ antagonism acts again to inhibit pyramidal neurons, but this time largely affecting GluN2A-containing NMDARs that are required for memory restabilization (Milton et al, 2013). Thus, CB1R antagonism should result in amnesia similar to that observed following the administration of drugs that enhance GABAergic signaling (Zhang and Cranney, 2008). This hypothesis is supported by our finding that antagonism at $\mathrm{GABA}_{\mathrm{A}}$ receptors rescued the AM251-induced deficit. Unlike previous work, we did not observe amnesia when BIC was administered alone; however, previous work targeting GABAergic signaling in reconsolidation (Bustos et al, 2006; Zhang and Cranney, 2008) has used systemic administration of GABAergic receptor antagonists rather than intracerebral infusions, as were used here. Furthermore, whether the transient memory 
enhancement produced by URB597 administration is also dependent upon GABAergic mechanisms remains a subject for future research.

We would argue that an alternative view-that the time dependence of the manipulation was simply because of the drugs being ineffective during the memory reactivation session when administered 30 min beforehand-is unlikely as both URB597 and AM251 have been shown to produce behavioral effects when administered intracranially at earlier time points relative to the behavioral session (Hasanein et al, 2007; Hohmann et al, 2005). Therefore, we suggest that the difference in the effects of CB1R antagonism-impairing destabilization or restabilization of the fear memorydepends more critically upon treatment timing.

There has been much discussion about the timing of administration of amnestic agents relative to memory reactivation in studies of reconsolidation (Finnie and Nader, 2012; Schiller and Phelps, 2011). We suggest that there is no theoretical requirement for treatment timing that determines whether reconsolidation is targeted or not; instead, the focus should be on whether the process of memory destabilization or restabilization is being targeted. Some amnestic agents, such as non-subtype selective NMDA receptor antagonists, prevent memory restabilization but not destabilization (Lee et al, 2006; Milton et al, 2008,2013 ) and administration before reactivation is more effective than administration after reactivation because NMDA receptor antagonism results in amnesia by blocking fast excitatory neurotransmission events at the point of reactivation. For other amnestic agents, such as protein synthesis inhibitors (Milekic and Alberini, 2002; Nader et al, 2000), where the onset of the process to be inhibited is slower, administration after reactivation is effective at disrupting restabilization. In this context, the effects of manipulating endocannabinoid signaling are unusual and of particular interest, because they can result in opposite effects on memory processes depending on the timing of antagonist administration. For example, for the consolidation of inhibitory avoidance memory, blocking CB1Rs in rat hippocampus and BLA with AM251 after training induces impairments in avoidance behavior (De Oliveira Alvares et al, 2008), but pretraining administration of AM251 facilitates consolidation (De Oliveira Alvares et al, 2008). A better understanding of the molecular mechanisms that underlie memory destabilization and restabilization, and how they interact with different neurotransmitter systems, such as the endocannabinoid system, will be more beneficial to future reconsolidation studies and translation to the clinic than assertions that all treatments must be given after reactivation in order to avoid effects on the separate and dissociable process of memory retrieval.

The data presented here clarify the requirement for endocannabinoid signaling in memory reconsolidation, and also indicate a novel target for the disruption of maladaptive memories that contribute to the persistence of psychiatric disorders such as PTSD (Brewin et al, 1996). Although additional investigations in other animal models of PTSD, and with systemic administration of the compounds used here, would be informative and would facilitate translation to the clinic, our data indicate that antagonizing $\mathrm{CB} 1 \mathrm{Rs}$ after memory reactivation may allow the disruption of old, well-established fear memories, reducing the persistence of the physiological and behavioral anxiety symptoms that characterize PTSD.

\section{FUNDING AND DISCLOSURE}

The authors declare no conflicts of interest.

\section{ACKNOWLEDGEMENTS}

We thank David Theobald and Alan Lyon for technical assistance. This work was conducted within the Behavioural and Clinical Neuroscience Institute, a joint initiative funded by the Wellcome Trust and the UK Medical Research Council, in the Department of Psychology at the University of Cambridge. This work was funded by a UK Medical Research Council programme grant (no. G1002231) awarded to BJE and ALM. PR was supported by a Department of Physiology and Pharmacology Fellowship at the Sapienza University of Rome, and an Italian Society of Pharmacology Fellowship. ALM is the Ferreras-Willetts Fellow in Neuroscience at Downing College, Cambridge. The manuscript was partly prepared while ALM was an Erskine Visiting Cambridge Fellow at the University of Canterbury, Christchurch, New Zealand.

\section{REFERENCES}

Arenos JD, Musty RE, Bucci DJ (2006). Blockade of cannabinoid CB1 receptors alters contextual learning and memory. Eur $J$ Pharmacol 539: 177-183.

Azad SC, Eder M, Marsicano G, Lutz B, Zieglgänsberger W, Rammes G (2003). Activation of the cannabinoid receptor type 1 decreases glutamatergic and GABAergic synaptic transmission in the lateral amygdala of the mouse. Learn Memory 10: 116-128.

Azad SC, Monory K, Marsicano G, Cravatt BF, Lutz B, Zieglgansberger $\mathrm{W}$ et al (2004). Circuitry for associative plasticity in the amygdala involves endocannabinoid signalling. J Neurosci 24: 9953-9961.

Barad M, Gean P-W, Lutz B (2006). The role of the amygdala in the extinction of conditioned fear. Biol Psychiatry 60: 322-328.

Ben Mamou C, Gamache K, Nader K (2006). NMDA receptors are critical for unleashing consolidated auditory fear memories. Nat Neurosci 9: 1237-1239.

Berlau DJ, McGaugh JL (2006). Enhancement of extinction memory consolidation: the role of the noradrenergic and GABAergic systems within the basolateral amygdala. Neurobiol Learn Mem 86: 123-132.

Bouton ME (1991). Context and retrieval in extinction and in other examples of interference in simple associative learning. In: Dachowski LFlaherty CF (eds) Current Topics in Animal Learning: Brain, Emotion and Cognition. Lawrence Erlbaum Associates: Hillsdale, NJ. pp. 25-53.

Brewin CR, Dalgleish T, Joseph S (1996). A dual representation theory of post traumatic stress disorder. Psychol Rev 103: 670-686.

Brunet A, Orr SP, Tremblay J, Robertson K, Nader K, Pitman RK (2008). Effect of post-retrieval propranolol on psychophysiologic responding during subsequent script-driven traumatic imagery in post-traumatic stress disorder. J Psychiatr Res 42: 503-506.

Bucherelli C, Baldi E, Mariottini C, Passani MB, Blandina P (2006). Aversive memory reactivation engages in the amygdala only some neurotransmitters involved in consolidation. Learn Mem 13: $426-430$. 
Bustos SG, Maldonado H, Molina VA (2006). Midazolam disrupts fear memory reconsolidation. Neuroscience 139: 831-842.

Campolongo P (2010). The role of endocannabinoids in the amygdala in the regulation of emotional memory. Eur Neuropsychopharmacol 20(Suppl 3): S169.

Campolongo P, Roozendaal B, Trezza V, Hauer D, Schelling G, McGaugh JL et al (2009). Endocannabinoids in the rat basolateral amygdala enhance memory consolidation and enable glucocorticoid modulation of memory. Proc Natl Acad Sci USA 106: $4888-4893$.

Cardinal RN, Aitken MRF (2006). ANOVA for the Behavioural Sciences Researcher. Lawrence Erlbaum Associates, Inc.: London.

Chhatwal JP, Davis M, Maguschak KA, Ressler KJ (2005). Enhancing cannabinoid neurotransmission augments the extinction of conditioned fear. Neuropsychopharmacology 30: 516-524.

Daskalakis NP, Yehuda R, Diamond DM (2013). Animal models in translational studies of PTSD. Psychoneuroendocrinology 38: 1895-1911.

De Oliveira Alvares L, Genro BP, Diehl F, Quillfeldt JA (2008). Differential role of the hippocampal endocannabinoid system in the memory consolidation and retrieval mechanisms. Neurobiol Learn Mem 90: 1-9.

Dębiec J, LeDoux JE (2004). Disruption of reconsolidation but not consolidation of auditory fear conditioning by noradrenergic blockade in the amygdala. Neuroscience 129: 267-272.

Dębiec J, LeDoux JE (2006). Noradrenergic signaling in the amygdala contributes to the reconsolidation of fear memory: treatment implications for PTSD. Ann N Y Acad Sci 1071: 521-524.

Dębiec J, LeDoux JE, Nader K (2002). Cellular and systems reconsolidation in the hippocampus. Neuron 36: 527-538.

Dickinson-Anson H, McGaugh JL (1997). Bicuculline administered into the amygdala after training blocks benzodiazepine-induced amnesia. Brain Res 752: 197-202.

Fattore L, Cossu G, Martellotta CM, Fratta W (2001). Intravenous self-administration of the cannabinoid CB1 receptor agonist WIN 55,212-2 in rats. Psychopharmacology 156: 410-416.

Finnie PSB, Nader K (2012). The role of metaplasticity mechanisms in regulating memory destabilization and reconsolidation. Neuroscie Biobehav Rev 36: 1667-1707.

Gale GD, Anagnostaras SG, Godsil BP, Mitchell S, Nozawa T, Sage JR et al (2004). Role of the basolateral amygdala in the storage of fear memories across the adult lifetime of rats. J Neurosci 24: $3810-3815$.

Hasanein P, Mohsen P, Keshavarz M, Javanmardi K (2007). CB1 receptor activation in the basolateral amygdala produces antinociception in animal models of acute and tonic nociception. Clin Exp Pharmacol Physiol 34: 439-449.

Hauer D, Ratano P, Morena M, Scaccianoce S, Briegel I, Palmery M et al (2011). Propofol enhances memory formation via an interaction with the endocannabinoid system. Anesthesiology 114: $1380-1388$.

Hohmann AG, Suplita RL, Bolton NM, Neely MH, Fegley D, Mangieri $\mathrm{R}$ et al (2005). An endocannabinoid mechanism for stress-induced analgesia. Nature 435: 1108-1112.

Johansen JP, Cain CK, Ostroff LE, LeDoux JE (2011). Molecular mechanisms of fear learning and memory. Cell 147: 509-524.

Katona I, Rancz EA, Acsády L, Ledent C, Mackie K, Hájos N et al (2001). Distribution of CB1 cannabinoid receptors in the amygdala and their role in the control of GABAergic transmission. J Neurosci 21: 9506-9518.

Kobilo T, Hazvi S, Dudai Y (2007). Role of cortical cannabinoid $\mathrm{CB} 1$ receptor in conditioned taste aversion memory. Eur $\mathrm{J}$ Neurosci 25: 3417-3421.

Lan R, Liu Q, Fan P, Lin S, Fernando SR, McCallion D et al (1999). Structure-activity relationships of pyrazole derivatives as cannabinoid receptor antagonists. J Med Chem 42: 769-776.
Lee JLC (2008). Memory reconsolidation mediates the strengthening of memories by additional learning. Nat Neurosci 11: 1264-1266.

Lee JLC, Di Ciano P, Thomas KL, Everitt BJ (2005). Disrupting reconsolidation of drug memories reduces cocaine seeking behavior. Neuron 47: 795-801.

Lee JLC, Milton AL, Everitt BJ (2006). Reconsolidation and extinction of conditioned fear: inhibition and potentiation. J Neurosci 26: 10051-10056.

Lewis DJ (1979). Psychobiology of active and inactive memory. Psychol Bull 86: 1054-1083.

Lin HC, Mao SC, Gean PW (2006). Effects of intra-amygdala infusion of CB1 receptor agonists on the reconsolidation of fearpotentiated startle. Learn Mem 13: 316-321.

Maćkowiak M, Chocyk A, Dudys D, Wedzony K (2009). Activation of CB1 cannabinoid receptors impairs memory consolidation and hippocampal polysialylated neural cell adhesion molecule expression in contextual fear conditioning. Neuroscience 158: $1708-1716$.

Mahan AL, Ressler KJ (2012). Fear conditioning, synaptic plasticity and the amygdala: implications for posttraumatic stress disorder. Trends Neurosci 35: 24-35.

Marsicano G, Wotjak CT, Azad SC, Bisogno T, Rammes G, Casclo MG et al (2002). The endogenous cannabinoid system controls extinction of aversive memories. Nature 418: 530-534.

Metna-Laurent M, Soria-Gómez E, Verrier D, Conforzi M, Jégo P, Lafenêtre $\mathrm{P}$ et al (2012). Bimodal control of fear-coping strategies by $\mathrm{CB}_{1}$ cannabinoid receptors. J Neurosci 32: 7109-7118.

Milekic MH, Alberini CM (2002). Temporally graded requirement for protein synthesis following memory reactivation. Neuron 36: 521-525.

Milton AL, Lee JLC, Butler VJ, Gardner RJ, Everitt BJ (2008). Intraamygdala and systemic antagonism of NMDA receptors prevents the reconsolidation of drug-associated memory and impairs subsequently both novel and previously acquired drug-seeking behaviors. J Neurosci 28: 8230-8237.

Milton AL, Merlo E, Ratano P, Gregory BL, Dumbreck JK, Everitt BJ (2013). Double dissociation of the requirement for GluN2Band GluN2A-containing NMDA receptors in the destabilization and restabilization of a reconsolidating memory. J Neurosci 33: 1109-1115.

Mor M, Rivara S, Lodola A, Plazzi PV, Tarzia G, Duranti A et al (2004). Cyclohexylcarbamic acid 3'- or 4'-substituted biphenyl3-yl esters as Fatty Acid Amide Hydrolase inhibitors: synthesis, quantitative structure-activity relationships, and molecular modeling studies. J Med Chem 47: 4998-5008.

Nader K (2003). Memory traces unbound. Trends Neurosci 26: 65-72.

Nader K, Schafe GE, LeDoux JE (2000). Fear memories require protein synthesis in the amygdala for reconsolidation after retrieval. Nature 406: 722-726.

Parsons RG, Ressler KJ (2013). Implications of memory modulation for post-traumatic stress and fear disorders. Nat Neurosci 16: $146-153$.

Paxinos G, Watson C (2004). The Rat Brain in Stereotaxic Coordinates, 5th ed. Academic Press: New York.

Piomelli D, Tarzia G, Duranti A, Tontini A, Mor M, Compton TR et al (2006). Pharmacological profile of the selective FAAH inhibitor KDS-4103 (URB597). CNS Drug Rev 12: 21-38.

Ratano P, Trezza V, Morena M, Manduca A, Miele J, Campolongo P et al (2011). Effects of central administration of the indirect cannabinoid agonist URB597 in the modulation of emotional memory in rats. Eur Neuropsychopharmacol 21(Supplement 3): S342-S343.

Schiller D, Monfils MH, Raio CM, Johnson DC, LeDoux JE, Phelps EA (2010). Preventing the return of fear in humans using reconsolidation update mechanisms. Nature 463: 49-54.

Schiller D, Phelps EA (2011). Does reconsolidation occur in humans? Front Behav Neurosci 5: 24. 
Suzuki A, Josselyn SA, Frankland PW, Masushige S, Silva AJ, Kida $S$ (2004). Memory reconsolidation and extinction have distinct temporal and biochemical signatures. J Neurosci 24: 4787-4795.

Suzuki A, Mukawa T, Tsukagoshi A, Frankland PW, Kida S (2008). Activation of LVGCCs and CB1 receptors required for destabilization of reactivated contextual fear memories. Learn Mem 15: 426-433.
Tan H, Lauzon NM, Bishop SF, Chi N, Bechard M, Laviolette SR (2011). Cannabinoid transmission in the basolateral amygdala modulates fear memory formation via functional inputs to the prelimbic cortex. J Neurosci 31: 5300-5312.

Zhang S, Cranney J (2008). The role of GABA and anxiety in the reconsolidation of conditioned fear. Behav Neurosci 122: 1295-1305. 